\title{
Arthroscopy of the hip in children and adolescents
}

\author{
Dennis R. Roy
}

Received: 30 July 2008/ Accepted: 8 October 2008/Published online: 18 November 2008 (C) EPOS 2008

\begin{abstract}
Intra-articular abnormalities of the hip, such as labral tears, loose bodies, chondral lesions, ligamentum teres tears and femoral acetabular impingement are increasingly being recognized in the pediatric age group. Evaluation for these abnormalities starts with a good history and physical exam. Radiographic imaging with plain films and magnetic resonance imaging help confirm the clinical impression. Arthroscopy of the hip can be utilized to diagnose and treat these abnormalities. Arthroscopy of the hip is a challenging procedure with a learning curve that requires a thorough knowledge of the anatomy of the hip. The hip is a deeply recessed joint that has a large muscular envelope, thick joint capsule and convex and concave surfaces of the femoral head and acetabulum, respectively. The normal anatomy may be distorted due to childhood developmental disorders such as hip dysplasia, Legg-Calve-Perthes Disease and Slipped Capital Femoral Epiphysis that adds additional challenges to the arthroscopist. Isolated intra-articular abnormalities occur rarely and an underlying morphologic abnormality should be identified which also requires management. Complications can be minimized with attention to detail.
\end{abstract}

Keywords Arthroscopic treatment . Arthroscopic findings · Hip disorders .

Children and adolescents

D. R. Roy $(\bowtie)$

Shriners Hospitals for Children, 3101 SW Sam Jackson Park

Road, Portland, OR 97239, USA

e-mail: droy@shrinenet.org

\section{Introduction}

The hip joint presents specific challenges to arthroscopic evaluation; the deeply recessed joint, thick joint capsule and the respective convex and concave surfaces of the femoral head and acetabulum. With refinement of techniques and the development of specialized instrumentation, arthroscopy of the adult hip has become established procedure for a variety of intra-articular problems [1-3]. Current indications in the adult hip include; labral tears, loose body removal, management of chondral flaps and osteochondral fractures, tears of the ligamentum teres, osteonecrosis, inflammatory arthritis, synovial chondromatosis, septic arthritis and management of femoral acetabular impingement (FAI).

The traditional method of managing intra-articular problems in children and adolescents has been an open arthrotomy, with or without, a surgical dislocation. Arthroscopy of the hip is being used more frequently in this age group because it is believed to be less invasive, has a lower morbidity with faster recovery, and provides excellent, if not better, visualization than an open procedure. The first experience in the pediatric age group was reported by Gross [4] in 1977. He used a 2.2-mm arthroscope and visualized the hip joint in a variety of childhood conditions including developmental dysplasia of the hip (DDH), Legg-Calve-Perthes Disease (LCPD), neuropathic subluxation, post sepsis, and in slipped capital femoral epiphysis (SCFE). Holgersson [5], in 1981, subsequently reported on his experience with chronic juvenile arthritis.

The indications for hip arthroscopy in children and adolescents are incompletely defined, but its role in managing disorders of the hip appears to be expanding. Intraarticular pathology most amendable to hip arthroscopy include labral tears, loose bodies, tears of the ligamentum 
teres and osteochondritis dissecans. Disorders most commonly associated with the above pathology include LCPD, SCFE, DDH, epiphyseal dysplasia and post trauma [6-8]. Hip pathology, typically seen in the adult, is also seen with pediatric sports injuries and idiopathic FAI.

\section{Patient assessment}

The goal is to differentiate intra-articular causes of discomfort from extra-articular etiologies through a thorough history and physical exam. Specific questions regarding description of the pain, its onset, precipitating factors (i.e., sitting, stairs, activities) and mechanical symptoms (i.e., catching, locking, popping and giving way) should be asked. Hip pain usually is located in the groin but may be referred distally to the thigh or knee. In this age group, the pain is frequently attributed to growing pains or a muscle strain. The patient should be asked to point out the location of their pain. Occasionally, the patient will demonstrate the " $\mathrm{C}$ " sign as described by Byrd [1] by holding their thumb and index finger in the shape of a " $\mathrm{C}$ " placing it over the greater trochanter.

On physical exam, palpate for tender areas over the pelvis and hip. Pain with the log roll maneuver indicates an intra-articular problem. The range of motion should be noted as well as recording the rotational profile, any leg length discrepancy and muscle atrophy. Trendelenburg's test, neurology exam and assessment of gait should also be performed.

Pain with flexion, adduction and internal rotation (impingement sign) is suggestive of an intra-articular problem or FAI. A positive McCarthy sign [9] is also suggestive of impingement. This sign is tested for by flexing both hips and then extending the tested hip, first in internal rotation and then external rotation. A positive sign is the reproduction of the patients' pain during extension. The flexion, abduction, external rotation (FABER) test or "figure of four" position tests for pathology, either at the sacroiliac joint or with tightness or pain from the psoas.

Conventional radiographs may give clues to the diagnosis and intra-articular derangements. Standard views include a supine AP pelvis and frog-leg lateral. Based on the underlying history (i.e., LCPD, DDH, SCFE) and physical exam, other views, such as a cross-table lateral, false profile, abduction/adduction and Dunn lateral (hips flexed $90^{\circ}$, abduction $20^{\circ}$ ) may be necessary.

The radiographs should be evaluated for dysplasia, impingement and malalignment. The femoral head-neck junction can be assessed on the cross-table, frog or Dunn laterals to identify a cam lesion [10-12]. The position of the anterior and posterior acetabular walls give information about the acetabular version. Acetabular retroversion is suggested by the cross-over and posterior wall signs. The pelvis view needs to be taken with neutral rotation and standardized pelvic inclination such that the distance between the symphysis and saccrococcygeal joint is approximately $32 \mathrm{~mm}$ in men and $47 \mathrm{~mm}$ in women. Otherwise, the cross-over sign and the posterior wall sign are inaccurate [13]. A computed tomography (CT) or magnetic resonance imaging (MRI) study can be obtained to confirm a suspected abnormality in the acetabular version. A CT however, raises concerns about radiation exposure.

Magnetic resonance imaging or magnetic resonance arthrography (MRA) are generally obtained to further assess or confirm the intra-articular problem. The preferred technique uses a high resolution surface coil in three planes (saggital, coronal and axial). MRA has been felt to provide a more sensitive and accurate picture.

Czerny et al. [14] reported on the accuracy of detection and staging of lesions of the acetabular labrum. Plain MRI and MRA were compared to the surgical findings in 22 cases. The authors reported a sensitivity of $90 \%$ and an accuracy of $91 \%$ with MRA compared to a $30 \%$ sensitivity and $36 \%$ accuracy with plain MRI. In a subsequent study, the MRA showed a sensitivity of $91 \%$, specificity of $71 \%$ and accuracy of $88 \%$. Keeney et al. [15] compared MRA versus the arthroscopic findings of 102 hips with labral pathology; the MRA showed a sensitivity of $71 \%$, specificity of $44 \%$, positive predictive value $93 \%$, negative predictive value $13 \%$ and an accuracy of $69 \%$. With respect to articular cartilage pathology, the MRA had a sensitivity of $47 \%$, specificity of $89 \%$, positive predictive value of $84 \%$ and negative predictive value of $59 \%$ and accuracy of 67\%. Mintz et al. [16] used a non-contrast MRI protocol in 92 patients prior to arthroscopy and reported that labral and chondral abnormalities can be successfully identified.

Magnetic resonance imaging or MRA is useful in the evaluation of the contour of the femoral head-neck junction in cases of suspected FAI. Ito et al. [17] described morphologic variations in the head-neck offset as seen on MRI, reporting a reduction in the offset in the lateral to anterior aspect of the neck in young men and in older women. Nötzli et al. [18] used MRI data to calculate the alpha angle as a measure of the head-neck contour.

Arthroscopy of the hip is indicated in the patient that has an appropriate history of pain with mechanical symptoms and signs. MRA may confirm an intra-articular problem but is not necessarily a pre-requisite. Contra-indications to arthroscopy include; joints with moderate to severe restriction of motion, heterotopic bone, significant joint space narrowing by $50 \%$ and major signs of osteoarthritis. Obesity is a relative contra-indication to the procedure. 


\section{Technique}

The procedure is performed under general anesthesia with muscle relaxation. Prophylactic antibiotics are not utilized. Either supine [19] or lateral [20] techniques can be used. The author uses the supine technique on a regular fracture table. The feet are anchored in boots, which often have to be tightened considerably to prevent slippage during the application of traction. Padding will help prevent neuropraxia developing in the feet. A well-padded perineal post is used and lateralized to the proximal thigh. The leg is positioned in slight flexion, abduction and internal rotation. The anatomy of the proximal femur may dictate the use of more or less abduction. The contralateral leg is abducted to accommodate positioning of the $\mathrm{C}$-arm between the legs. A small amount of traction is applied to this limb. Traction is applied to the operative side until the joint is distracted approximately $1 \mathrm{~cm}$. The force that is necessary in the adult is variable and averages between 25 and 100 pounds of pressure $[1,21,22]$. There is no comparable data for the pediatric age group.

The author generally uses two portals, anterolateral and anterior. The C-arm is used to help guide the portal placement (Fig. 1). The anterolateral portal is placed first and is the safest in regard to neurovascular structures. This portal is placed at the proximal anteromedial margin of the greater trochanter. After this portal is established, the remaining portals can be made under direct vision (Fig. 2). The anterior portal is made at the intersection of a saggital line drawn down the leg through the anterior superior iliac spine and a transverse line drawn perpendicular to the body across the tip of the greater trochanter. Distal anterior and posterolateral portals are the most commonly used auxiliary portals. The anatomy of the various portals and proximity to neurovascular structures has been described by Byrd [23].

Portal development is made using a long spinal needle through which a guide wire can be inserted. The capsule is thick, but has a different consistency than the bone or labrum. The needle placement should not transgress the labrum. The cannulated system allows the obturator/cannula assembly to be introduced into the joint over the guide wire. Seventy and $30^{\circ}$ arthroscopes are routinely used and freely exchanged between the portals for complete visualization of the joint. The portals are enlarged by passing an arthroscopic knife into the joint through the cannula. The cannula is then retracted to allow the capsular incision under direct vision of the arthroscope. This procedure improves the mobility of the arthroscope and instrumentation. An arthroscopic fluid pump is routinely used and maintained at a pressure between 40 and $60 \mathrm{~mm} \mathrm{Hg}$. There are no reported standards for pressure settings in the pediatric age group. Epinephrine is added to the fluid to

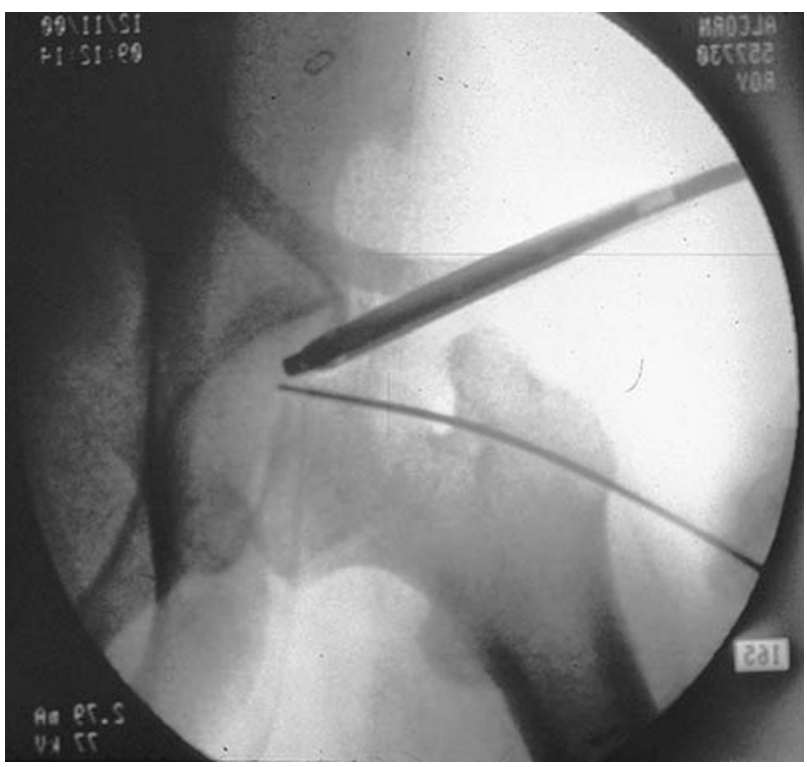

Fig. 1 X-ray view showing joint distraction of $1 \mathrm{~cm}$, the arthroscope in the anterolateral portal, and localization needle for the anterior portal

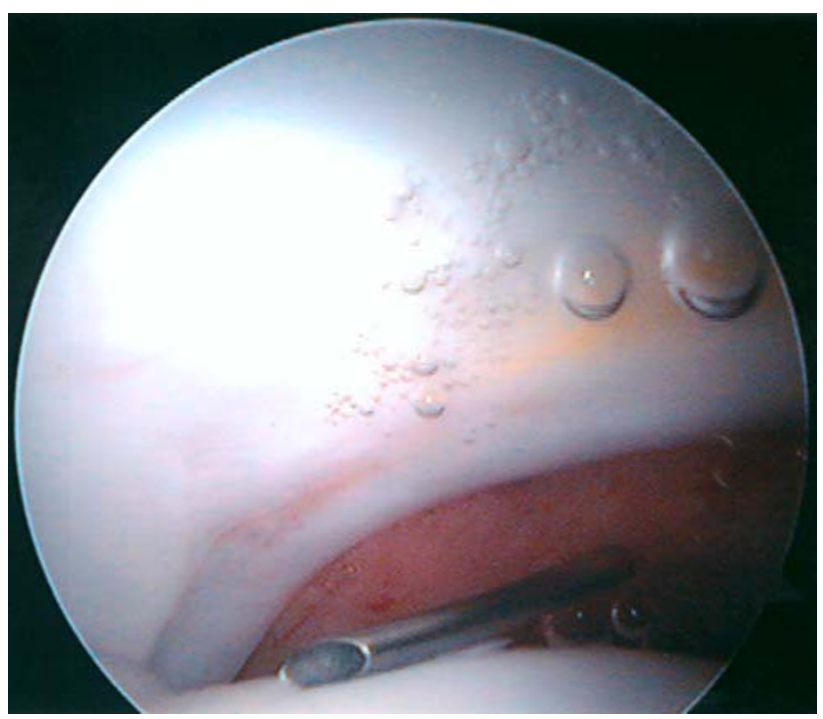

Fig. 2 View from the anterolateral portal showing localization needle for the anterior portal

minimize blood obscuring visability. Specialized instrumentation including motorized shavers, burrs and flexibletip electrocautery devices are utilized.

The hip joint is divided into the central compartment (the intra-articular region) and the peripheral compartment (the intracapsular but extra-articular region). A thorough inspection of the central compartment is performed first with the hip distracted. A systematic approach should be developed to evaluate the labrum (Fig. 3), fovea (Fig. 4), ligamentum teres (Fig. 5), the articular surfaces of the femoral head and acetabulum and joint recesses [24, 25]. 


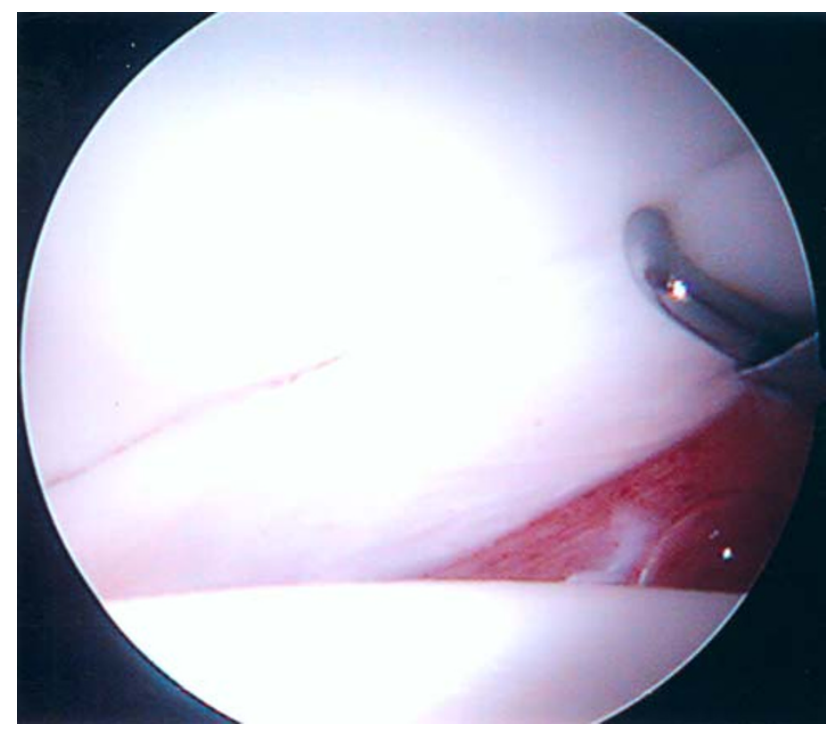

Fig. 3 A surgical probe is evaluating the labrum acetabular junction

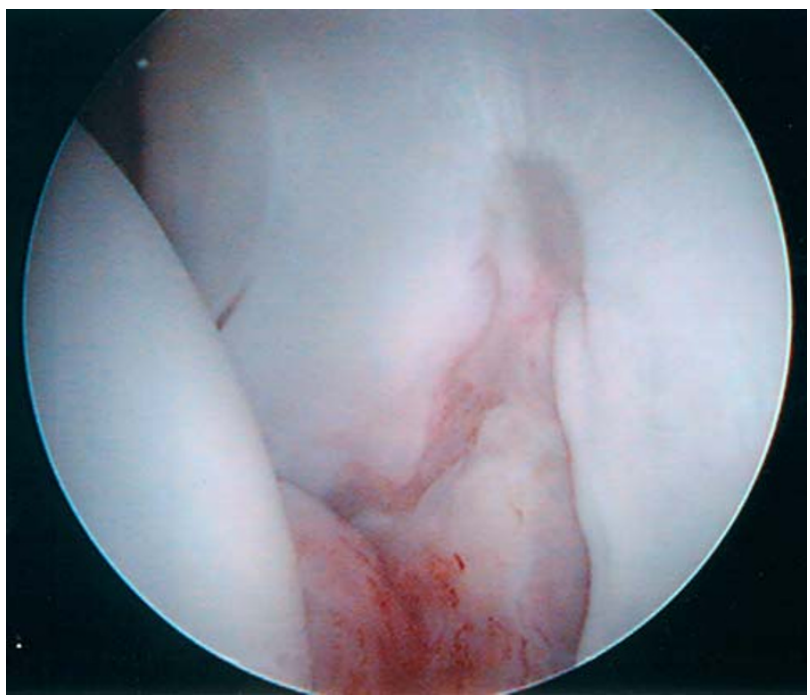

Fig. 4 View of fovea and acetabulum

Cartilage changes are recorded according to the Outerbridge classification [26]. The location and recording of the intra-articular pathology has generally been the clock face method. More recently, a geographic zone method has been developed [27]. After completion of the procedure in the central compartment, the arthroscope is positioned into the peripheral compartment and the traction released (Fig. 6). The hip is flexed to approximately $45^{\circ}$ to relax the capsule allowing visualization (Fig. 7). It is not enough to identify an intra-articular abnormality. Isolated injuries do occur, but a search for an underlying morphologic variation needs to undertaken. A dynamic assessment should be made of the joint from within the peripheral compartment by moving the hip in all motion planes looking for evidence of

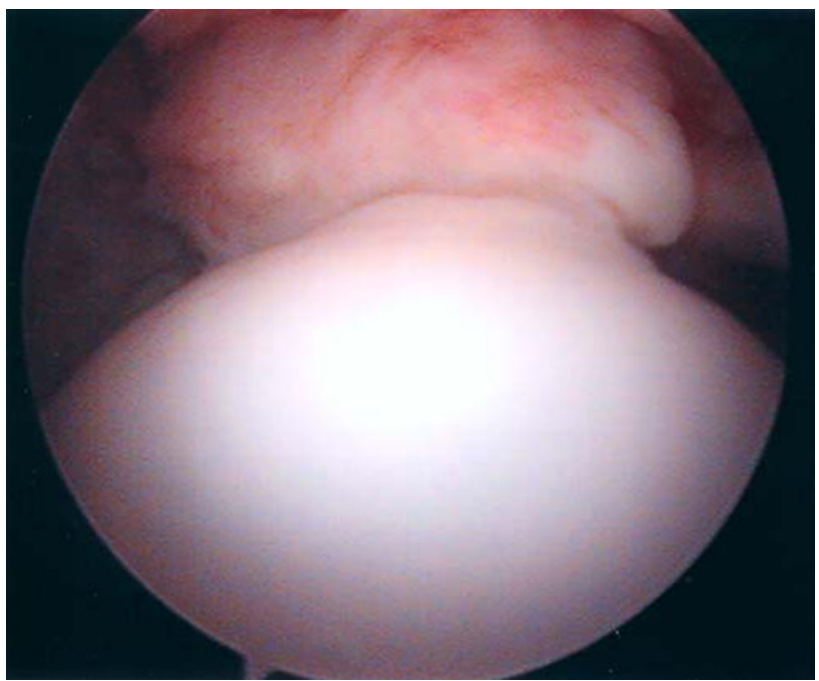

Fig. 5 View of ligamentum teres and femoral head

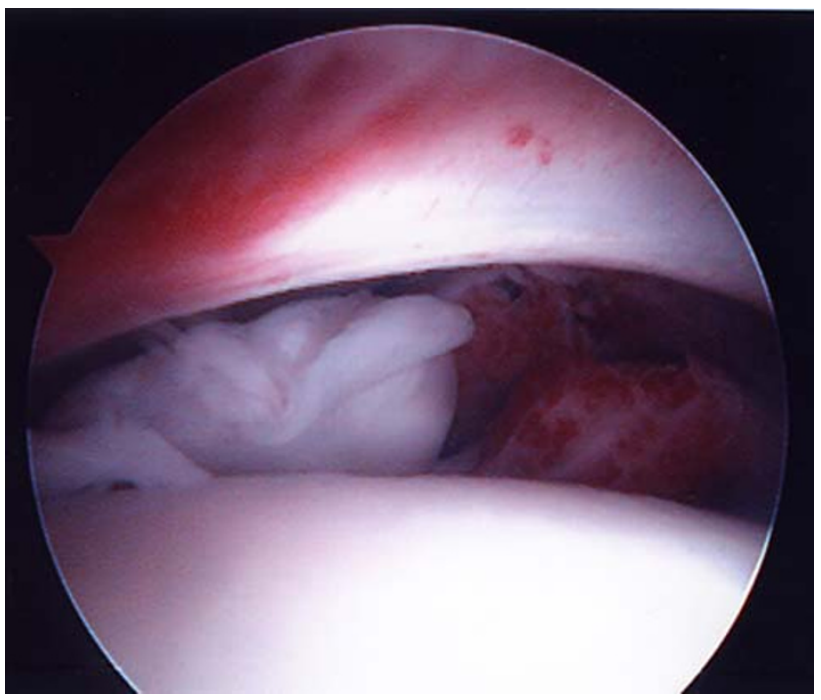

Fig. 6 View from peripheral compartment prior to release of traction. Note the femoral head, torn ligamentum teres and the intact labrum

FAI. The abnormal femoral head-neck offset in cam type FAI can often be best visualized with the hip flexed approximately $45^{\circ}$ (Fig. 8). An osteoplasty for a cam lesion is performed using a motorized burr from superior to inferior along the femoral head-neck junction. Enough bone is removed to relieve the impingement and is generally a depth of 5-6 mm with a width of approximately $1 \mathrm{~cm}$ (Fig. 9).

At the end of the procedure, the hip joint and soft tissues are injected with a long acting anesthetic agent. Caution is necessary in selecting an appropriate agent. Bupivacaine has recently been reported to be toxic to human articular chondrocytes and a less toxic agent should be chosen [28]. The portals are closed in a standard fashion and dressings 


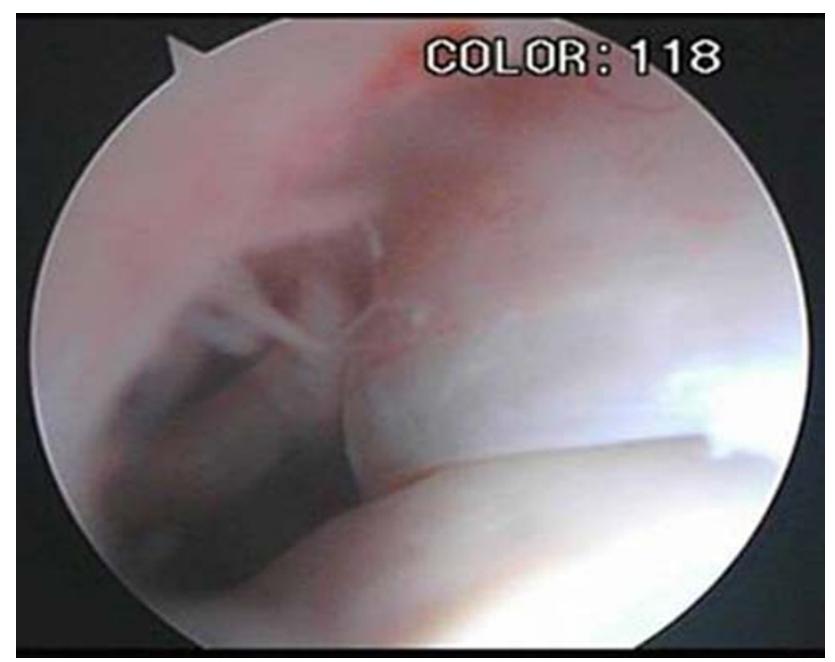

Fig. 7 View from peripheral compartment with traction released. Note the femoral head and labrum

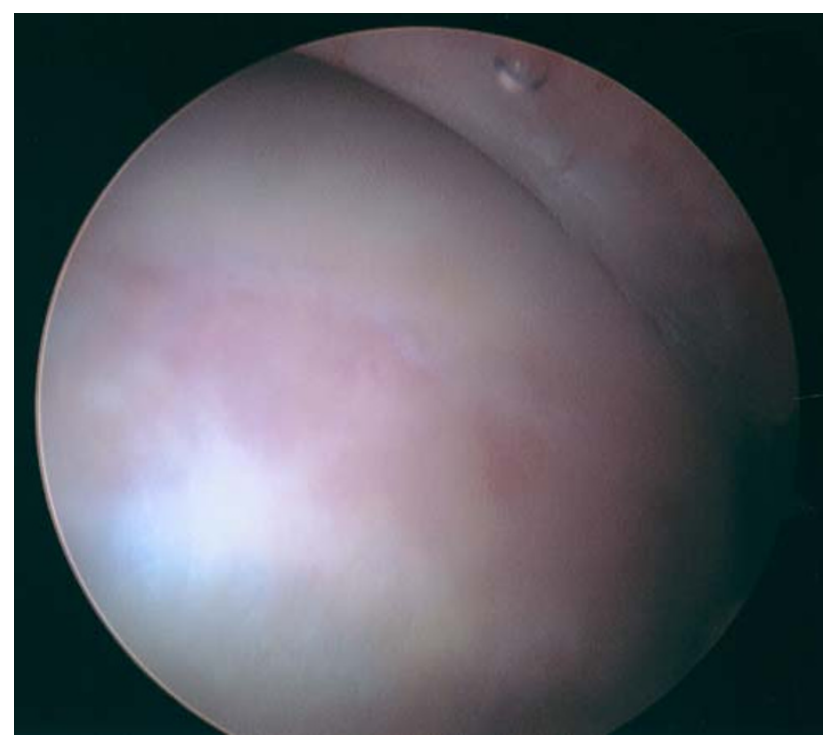

Fig. 8 View of femoral head neck junction

applied. Extravasated fluid will tend to saturate the dressings over several hours. The patients and their families should be cautioned about this.

The postoperative management is directly related to the pathology identified and the subsequent arthroscopic management. In debridement procedures, crutches are used as needed, followed by range of motion and subsequent strengthening of the hip musculature by closed-chain exercises. In procedures where there has been recontouring of the head-neck junction or a labral repair, crutches are utilized for 4-6 weeks. Range of motion is encouraged on a stationary bike, without resistance, early in the recovery period. Closed-chain exercises are started later.

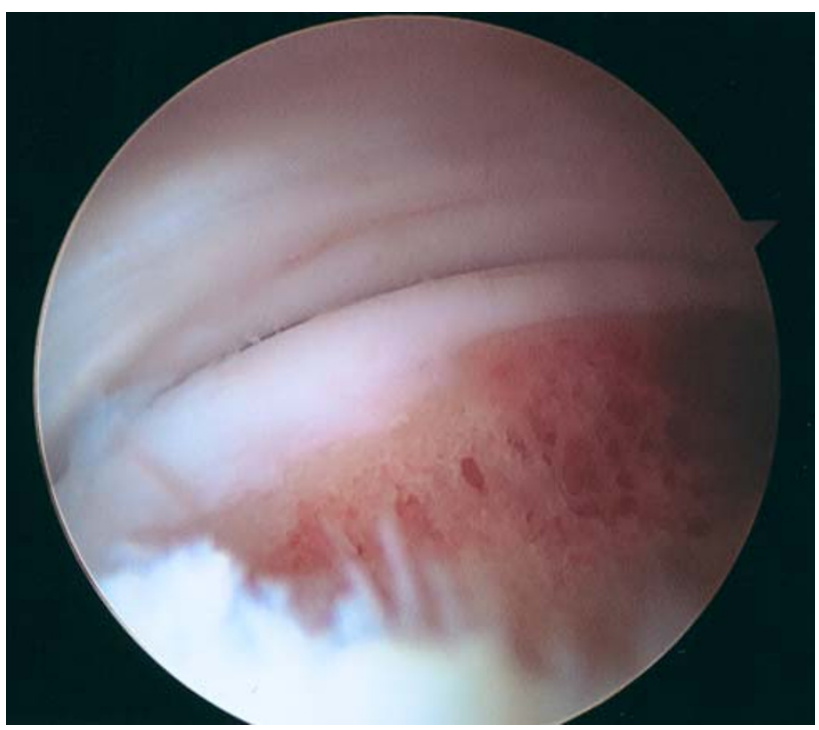

Fig. 9 Osteoplasty for relief of cam impingement

Preoperative signs and symptoms generally are improved in about 3 months.

\section{Complications}

Potential complications of the procedure can be divided into those related to the traction, or to the procedure directly $[1,29,30]$. Traction-related problems include transient or permanent neuropraxias or palsies to the sciatic, femoral and pudendal nerves. The lateral femoral cutaneous nerve can also be damaged during creation of the anterior portal. The author has had several cases of foot neuropraxias related to compression from the traction boots. Pressure from the peroneal post has been reported to cause areas of necrosis and anal and vaginal tears have also been reported [1]. Traction-related complications can be minimized by appropriate padding and positioning, limiting the distraction force to only what is necessary and keeping the traction time to as short a time as possible.

Labral damage can occur during insertion of the cannulas, thus the importance of generating the portals under direct vision. Damage to the articular surfaces from the arthroscope and instrumentation can easily occur and must be minimized. There is a tendency to lever with the arthroscope and instrumentation to negotiate around the femoral head. Capsular incisions will help increase the mobility of the arthroscope and instruments, but attention to detail will help minimize iatrogenic damage. Complications related to fluid extravasation have also been reported [1].

The additional risks with an osteoplasty of the femoral head-neck junction include AVN and femoral neck fracture 
[31]. Mardones et al. [32] have reported that up to $30 \%$ resection of the anterolateral quadrant of the head-neck junction did not significantly alter the load bearing capacity of the proximal part of the femur. There was a decrease in the amount of energy required to fracture. Other complications include adhesions at the capsulolabral margin and capsule with the region of bony resection [31].

\section{Discussion}

A list of the diagnoses and the author's experience is listed in Table 1. All patients had mechanical symptoms and a positive impingement test. The goal of the arthroscopic procedure was to identify the intra-articular pathology, the pattern of damage and to treat the etiology through subsequent reconstructive surgery if it could not be treated at the same time. The intra-articular pathology was treated with debridement or repair. The arthroscopic findings assisted in the planning of the subsequent surgery.

\section{Hip dysplasia}

Adolescent hip dysplasia frequently leads to pain related to a torn labrum (Fig. 10) or chondral abnormality. The intraarticular pathology may compromise the results of acetabular re-alignment or augmentation if left untreated [5, $33,34]$. I have preferred to evaluate the intra-articular pathology prior to the reconstructive procedure due to the excellent visibility provided by the arthroscopy of not only the labrum, but also the status of the cartilage of the acetabulum and femoral head. The choice of reconstructive or salvage procedure may be influenced by the extent of the changes identified in the articular cartilage. Labral repair is indicated where feasible.

Arthroscopy of the hip has been recently reported in the management of DDH in three children $<2$ years of age [35]. The authors report their indication is for failure of closed reduction. The pathoanatomy could be visualized and they were able to perform a limited debridement of the ligamentum teres and the pulvinar. Subsequently, the hips

Table 1 List of diagnoses and number or arthroscopic cases

\begin{tabular}{lc}
\hline Diagnosis & No. of arthroscopic cases \\
\hline DDH & 52 \\
LCPD & 42 \\
MED/SED & 9 \\
SCFE & 8 \\
AVN & 6 \\
FAI & 4 \\
Other & 22 \\
\hline
\end{tabular}

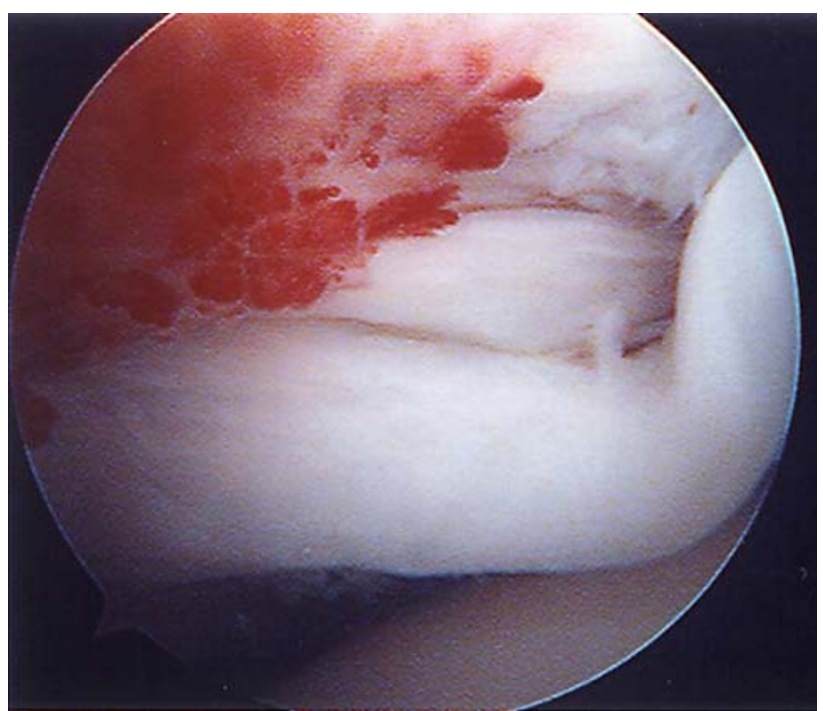

Fig. 10 Torn labrum in patient with adolescent DDH

were felt to stabilize more easily. The authors recommended caution in interpreting their results. I have no experience with hip arthroscopy in this age group but find the concept intriguing. In addition to debridement of the ligamentum teres and pulvinar, other obstacles to a successful closed reduction could be treated by releasing the iliopsoas and transverse acetabular ligament.

\section{Legg-Calve-Perthes disease}

Arthroscopic findings of the hip have been described in the early stages of LCPD. Gross [4] reported areas of flattening of the femoral head, cartilage fibrillation and dilation of the perichondral vascular ring, while Suzuki [36] found proliferation of the synovium and hypervascularity of the labrum. At this time there is little indication for arthroscopy of the hip in children with active LCPD. Adolescents and young adults, however, may present with mechanical signs and symptoms due to sequelae of earlier LCPD and benefit from arthroscopic management. A variety of intraarticular findings has been described [37-40]. Acetabular labral tears, tears of the ligamentum teres (Fig. 11), loose bodies, osteochondritis dissecans, chondral flaps, chondromalacia and groove defects of the femoral head (Fig. 12) are due to the disease process, and are amenable to arthroscopic treatment. The pattern of abnormality or damage can help plan subsequent reconstructive procedures. I have not performed an osteoplasty of the femoral head for LCPD, but have tended to debride the intraarticular abnormalities in a few instances and over coverage by the acetabulum was resected. The residual deformity of the proximal femur (coxa magna, coxa breva), often makes a full assessment of the peripheral compartment more difficult. 


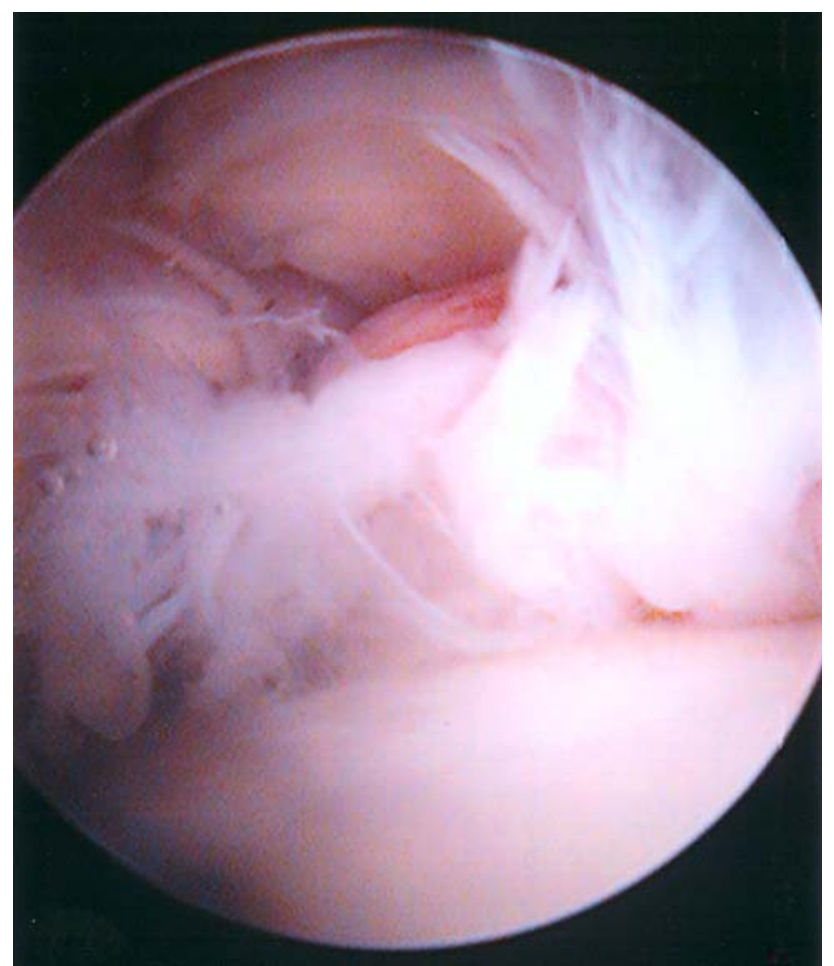

Fig. 11 Tear of ligamentum teres

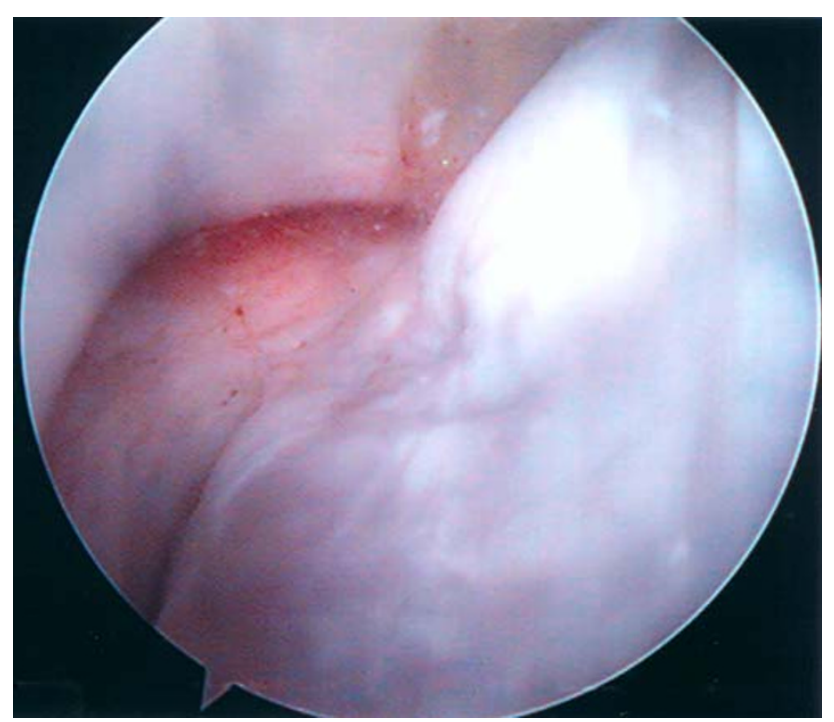

Fig. 12 Groove defect of femoral head in LCPD

\section{Epiphyseal dysplasia}

In multiple epiphyseal dysplasia (MED) and spondyloepiphyseal dysplasia (SED), chondral flaps or loose bodies may occur (Fig. 13). Chondral fracture and delamination of the femoral head can occur suddenly with normal daily activities [41]. Arthroscopy can be used to remove the loose bodies and debride the chondral flaps. Avascular

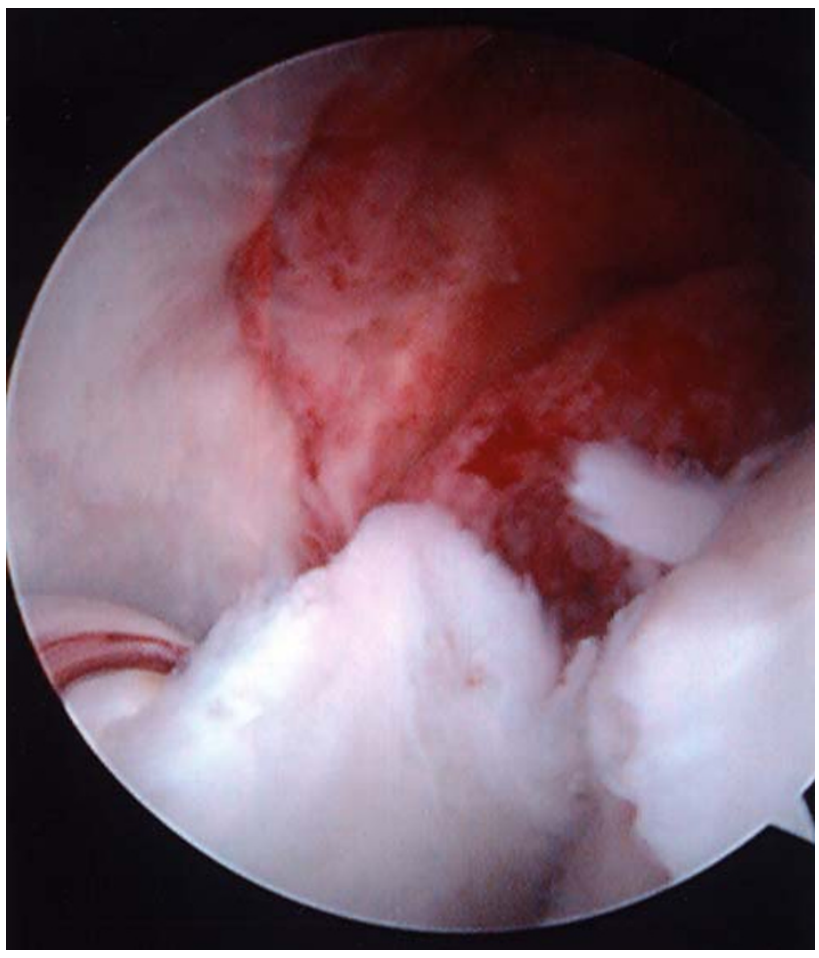

Fig. 13 Large loose body from femoral head in patient with SED

necrosis may also occur in conjunction with MED and SED [42] leading conceptually, to further deformity of the femoral head and subsequent impingement type lesions as seen in LCPD.

Slipped capital femoral epiphysis

Futami [43], in 1992, reported his arthroscopic findings in patients presenting with a SCFE. The arthroscopy was performed prior to pinning of the slip and revealed erosion of the acetabular cartilage in the anterosuperior region and damage to the posterolateral aspect of the acetabular labrum. He also reported cartilaginous erosions and a transverse cleft on the anterior surface of the femoral head. Rab [44] used a mathematical model to study the geometry of SCFE and raised the concepts of impaction and inclusion. With impaction, the deformity could lead to erosion of the anterolateral acetabulum. With mechanical levering, there may be erosions in the anterosuperior acetabular cartilage and damage or detachment of the posterolateral acetabular labrum. Leunig [45] found a constant pattern of mechanical damage when doing a surgical dislocation for the management of 14 hips with SCFE. He reported damage to the labrum and either partial or full thickness loss of the adjacent acetabular cartilage. In my experience, similar changes were seen at arthroscopy. Arthroscopic osteoplasty may be beneficial in patients with previously stabilized mild slips that present with impingement signs and symptoms. In healed slips with more 
significant deformity, a realignment osteotomy is indicated and an arthroscopic debridement of the intra-articular abnormalities can be performed as a conjunct.

\section{Avascular necrosis}

Ruch et al. [46] reported on the use of arthroscopy of the hip in avascular necrosis and developed a staging classification for the feasibility of performing a revascularization procedure. Kloen [47] noted anterosuperior flattening of the femoral heads which reduced the head neck ratio leading to cam impingement. A consistent pattern of labral pathology and acetabular chondral damage correlated with the femoral head changes. McCarthy [48] advocated arthroscopic treatment and/or staging of AVN in those patients with mechanical symptoms and signs. I have utilized an arthroscopic assessment of the hip in patients with mechanical symptoms in conjunction with core decompression.

\section{Trauma}

Arthroscopy of the hip for removal of retained loose bodies has been reported following hip dislocations and fracture dislocations in adults [49-52]. The procedure for removal has generally been performed at approximately three weeks post injury, due to the concern for excessive extravasation of fluid into the soft tissues and intra-abdominally [52]. In the pediatric age group, arthrotomy has generally been recommended for incongruent reductions. Torn ligamentum teres, osteochondral fragments and acetabular epiphysis-labrum, have been reported as being interposed, blocking the reduction [53-55]. Kashiwagi [56] reported on the arthroscopic removal of an avulsion fracture of the ligamentum teres following traumatic dislocation in a 10year old. The author has experience with just two cases. One patient, age 9, had persistent hip pain following an open arthrotomy and removal of a loose body following an incongruous closed reduction. At arthroscopy, 6-months later, a torn and detached posterior labrum was debrided with resolution of the pain and a return to full activities. The second patient, age 16, presented 6-months following concentric reduction of a traumatic dislocation with pain and impingement symptoms and signs. At arthroscopy, a tear of the posterior labrum and ligamentum teres was indentified as well as a large impaction lesion on the anterior femoral head. This patient continues with hip pain following debridement and microfracture of the femoral head lesion.

\section{Sports injuries}

Arthroscopy in the management of athletic hip injuries has been reported in the adult population [57-60] with only a few references in the pediatric athlete [5, 61]. Pediatric and adolescent athletes may develop intra-articular hip problems from an isolated athletic injury or repetitive traumatic activity leading to labral tears, chondral or osteochondral lesions and tears of the ligamentum teres. Sports that involve repetitive flexion, flexion-abduction and extensionexternal rotation may be especially at risk. Isolated labral tears occur, but some author's caution that they occur infrequently and a search for an underlying morphologic abnormality (i.e., CAM impingement) should be ruled out [60, 62]. Arthroscopic debridement of labral tears has been reported to relieve pain and improve function [63-65]. Byrd [65], in adults, and Kocher [8], in children and adolescents, have reported improvement in the modified Harris Hip Score (HHS) with arthroscopic debridement of labral tears. The current emphasis is on labral repair [66, 67].

Femoral acetabular impingement

A common indication for hip arthroscopy in the adult is for the management of FAI. Two distinct types of FAI have been identified; cam and pincer [68]. Cam type impingement is caused by a reduced head-neck offset. Siebenrock et al. [69] noted that morphologic abnormalities in the shape of the head-neck junction was caused by an abnormal extension of the capital femoral epiphysis of unknown etiology. This abnormal contour of the femoral head-neck junction impinges against the acetabular rim with flexion and flexion internal rotation movement of the hip. This shearing force has been found to produce a reproducible pattern of damage to the anterosuperior acetabular rim of chondral avulsion and secondarily labral tear or detachment. Pincer type impingement is caused by an acetabular abnormality resulting in overcoverage of the femoral head. This can be related to a generalized protrusion or acetabular retroversion. The retroversion may be primary or secondary to previous reconstructive surgery. Impact between the femoral head and the anterior overcoverage leads to degeneration and tears of the labrum. The labrum may be hypoplastic and subsequent ossification of the rim may worsen the impingement. A contre-coup chondral lesion may develop to the posterior-inferior head or acetabulum. Both types of FAI have been associated with progressive joint degeneration [70, 71].

The standard treatment for FAI is an open surgical dislocation with labral repair in the cam lesions and labral re-fixation in the pincer lesions [72]. More recently, arthroscopic approaches have been reported in the adult population $[62,73]$. The authors' experience is limited to four patients with primary FAI; three cam and one pincer. Both cam and pincer impingement can be seen following pelvic osteotomies such as a triple or PAO [74]. 
Both types of FAI are increasingly being recognized in the adolescent population. My limited experience in primary FAI has been with cam lesions that were treated with an arthroscopic osteoplasty. FAI in patients with an underlying diagnosis have often been encountered both pre and post reconstruction.

Septic arthritis

Arthroscopic lavage has been utilized in the management of septic arthritis of the hip. Several small series in the adult have been published reporting successful outcomes [75-77]. There are several reports in the use of arthroscopic lavage and drainage in the pediatric age group. Chung [78], in 1993, published the effectiveness of ablating infection in nine patients, ages $2-7$, following high volume arthroscopic lavage, followed by 3-6 weeks of antibiotic treatment. Kim [79] reported excellent results and no complications in eight patients 2-14 years old, treated with arthroscopic drainage and debridement. More recently, ElSayed [80] reported a comparison study of 20 hips treated with antibiotics and either open arthrotomy or arthroscopic drainage. At 12 month minimum follow-up, there was no statistical difference in the outcome. Hospital stay, however, was shorter in the arthroscopic group. My practice in Pediatric Orthopedics is at a tertiary care facility and I do not see patients with this diagnosis.

Other reported uses of hip arthroscopy in children and adolescents include excision of exostoses within the acetabular fossa in patients with hereditary multiple exostosis [81] and the management of inflammatory and synovial based disorders [82]. Krebs reviewed the role of hip arthroscopy in the treatment of synovial disorders and loose bodies [83].

\section{Outcomes}

There are no validated outcome measures specific to arthroscopy. The modified HHS has frequently been used to report outcomes. This score was developed for mold arthroplasty patients. In its modified form, pain and function are measured and converted to a 100-point scale. Kocher [8] used the modified HHS to report the outcomes in a heterogeneous group of hip disorders in children and adolescents. Scores improved from 53.1 to 82.9 with debridement of the intra-articular abnormalities with at least 1-year of follow-up. More recently Yen et al. [84] reported the results of 12 hips in patients 16 years or less with FAI using the modified HHS and a hip outcome score (HOS) activities of daily living (ADL) with follow-up ranging between 1 and 2 years. The modified HHS improved from 52 to 90 and the HOS ADL from 57 to 95.
In my heterogeneous group of patients, no outcome measures are being reported. Many of the patients undergoing arthroscopy had subsequent reconstructive surgery. Newer outcome measures are being developed specific to hip arthroscopy $[85,86]$.

\section{Conclusion}

Arthroscopy of the hip has become a standard procedure in the adult population for a variety of hip conditions. The indications and use of arthroscopy in children, adolescents and young adults continues to evolve. In the adult population for which arthroscopy is performed, the anatomy tends to be quite uniform. In children and adolescents, the underlying anatomy is more frequently abnormal due to the pre-existing disorders and their treatment. The landmarks are also frequently altered due to the large number of patients that have had previous surgery, either femoral or acetabular. There is a learning curve to this procedure. After obtaining specialty training in hip arthroscopy; attending continuing educational courses and cadaver labs, and 10-years of performing arthroscopy in a practice focused on hip deformity, I continue to find the procedure to be challenging. The procedure can be performed safely if there is attention to detail on the padding, positioning and time in traction. Care must be taken in developing portals to minimize damage to the soft tissues and labrum and avoiding iatrogenic damage to the cartilaginous joint surfaces, especially the femoral head, with the arthroscope, cannulas or instruments. Mobility of the arthroscope and instruments can be improved by increasing the size of the arthrotomies with an arthroscopic knife. Diagnoses in which arthroscopy of the hip can play a role include: DDH, LCPD, SCFE, MED and SED, AVN, loose bodies, trauma, inflammatory, FAI and labral tears. The intra-articular findings can also be used to guide future reconstructive surgery of the hip. Hip arthroscopy is also a useful adjunct to evaluating pain post reconstruction especially for impingement lesions. It must be remembered that the intraarticular pathology (i.e., labral tears) is secondary to an underlying abnormal bony morphology [87, 88]. Failure to recognize and address this abnormal bony morphology will result in a failed procedure and poor outcome.

\section{References}

1. Byrd JW (2005) Operative hip arthroscopy, 2nd edn. Springer, Berlin

2. Khanduja V, Villar RN (2006) Arthroscopic surgery of the hip: current concepts and recent advances. J Bone Joint Surg Br 88B:1557-1566. doi:10.1302/0301-620X.88B12.18584 
3. Kelly BT, Williams RJIII, Philippon MJ (2003) Hip arthroscopy: current indications, treatment options and management issues. Am J Sports Med 31:1020-1037

4. Gross R (1977) Arthroscopy in hip disorders in children. Orthop Rev 6:43-49

5. Holgersson S, Brattström H, Mogenson B, Lidgren L (1981) Arthroscopy of the hip in juvenile chronic arthritis. J Pediatr Orthop 1:273-278

6. Kocher MS, Kim YJ, Millis MB, Mandiga R, Siparsky P, Micheli LJ, Kasser JR (2005) Hip arthroscopy in children and adolescents. J Pediatr Orthop 25:680-686. doi:10.1097/01.bpo.0000 161836.59194 .90

7. DeAngelis NA, Busconi BD (2003) Hip arthroscopy in the pediatric population. Clin Orthop Relat Res 406:60-63. doi:10.1097/00003086-200301000-00010

8. Schindler A, Lechevallier JJ, Rao NS, Bowen JR (1995) Diagnostic and therapeutic arthroscopy of the hip in children and adolescents: evaluation of results. J Pediatr Orthop 15:317321

9. McCarthy JC (2003) Early hip disorders, advances in detection and minimally invasive treatment. Springer, Berlin

10. Eijer H, Leunig M, Mahomed MN, Ganz R (2001) Cross-table lateral radiographs for screening of anterior femoral head-neck offset in patients with femoroacetabular impingement. Hip Int $11: 37-41$

11. Meyer DC, Beck M, Ellis T, Ganz R, Leunig M (2006) Comparison of six radiographic projections to assess femoral/head neck asphericity. Clin Orthop Relat Res 445:181-185

12. Clohisy JC, Nunley RM, Otto RJ, Schoenecker PL (2007) The frog-leg lateral radiograph accurately visualized hip cam impingement abnormalities. Clin Orthop Relat Res 462:115-121. doi:10.1097/BLO.0b013e3180f60b53

13. Siebenrock KA, Kalbermatten DF, Ganz R (2003) Effect of pelvic tilt on acetabular retroversion: a study of pelvis from cadavers. Clin Orthop Relat Res 407:241-248. doi:10.1097/0000 3086-200302000-00033

14. Czerny C, Hofmann S, Neuhold A et al (1996) Lesions of the acetabular labrum: accuracy of MR and MR arthrography in detection and staging. Radiology 200:225-230

15. Keeney JA, Peelle MW, Jackson J, Rubin D, Maloney WJ, Clohisy JC (2004) Magnetic resonance arthrography versus arthroscopy in the evaluation of articular hip pathology. Clin Orthop Relat Res 429:163-169. doi:10.1097/01.blo.0000 150125.34906.7d

16. Mintz DN, Hooper T, Connell D, Buly R, Padgett DE, Potter HG (2005) Magnetic resonance imaging of the hip: detection of labral and chondral abnormalities using non-contrast imaging. Arthroscopy 21:385-393. doi:10.1016/j.arthro.2004.12.011

17. Ito K, Minka MAII, Leunig M, Werlen S, Ganz R (2001) Femoroacetabular impingement and the cam effect. A MRI-based quantitative anatomical study of the femoral head-neck offset. J Bone Joint Surg Br 83:171-176. doi:10.1302/0301-620X. 83B2.11092

18. Nötzli HP, Wyss TF, Stoecklin CH, Schmid MR, Trieber K, Hodler J (2002) The contour of the femoral head-neck junction as a predictor for the risk of anterior impingement. J Bone Joint Surg Br 84:551-560

19. Byrd JW (1994) Hip arthroscopy utilizing the supine position. Arthroscopy 10:275-280. doi:10.1016/S0749-8063(05)80111-2

20. Glick JM, Sampson TG, Gordon RB, Behr JT, Schmidt E (1987) Hip arthroscopy by the lateral approach. Arthroscopy 3:4-12. doi:10.1016/S0749-8063(87)80003-8

21. Mason JB, McCarthy JC, O'Donnell JO et al (2003) Hip arthroscopy: surgical approach, positioning, and distraction. Clin Orthop Relat Res 406:29-37. doi:10.1097/00003086-2003 01000-00007
22. Eriksson E, Arvidsson I, Arvidsson H (1986) Diagnostic and operative arthroscopy of the hip. Orthopedics 9:169-176

23. Byrd JW, Pappas JN, Pedley MJ (1995) Hip arthroscopy: an anatomic study of portal placement and relationship to the extraarticular structures. Arthroscopy 11:418-423. doi:10.1016/07498063(95)90193-0

24. Keene GS, Villar RN (1994) Arthroscopic anatomy of the hip: an in vivo study. Arthroscopy 10:392-394. doi:10.1016/S0749-8063 (05)80189-6

25. Dvorak M, Duncan CP, Day B (1990) Arthroscopic anatomy of the hip. Arthroscopy 6:264-273. doi:10.1016/0749-8063(90) 90055-I

26. Outerbridge RE (1961) The etiology of chondromalacia patellae. J Bone Joint Surg Br 43:752-757

27. Ilizaliturri VM Jr, Byrd JW, Sampson TG, Guanche CA, Philippon MJ, Kelly BT et al (2008) A geographic zone method to describe intra-articular pathology in hip arthroscopy: cadaveric study and preliminary report. Arthroscopy 24:534-539. doi:10.1016/j.arthro.2007.11.019

28. Piper SL, Kim HT (2008) Comparison of ropivicaine and bupivacaine toxicity in human articular chondrocytes. J Bone Joint Surg 90:986-991. doi:10.2106/JBJS.G.01033

29. Clarke MT, Arora A, Villar RN (2003) Hip arthroscopy: complications in 1054 cases. Clin Orthop Relat Res 406:84-88. doi:10.1097/00003086-200301000-00014

30. Sampson TG (2001) Complications of hip arthroscopy. Clin Sports Med 20:831-835. doi:10.1016/S0278-5919(05)70288-X

31. Philippon M, Schenker M, Briggs K, Kuppersmith D (2007) Femoroacetabular impingement in 45 professional athletes: associated pathologies and return to sport following arthroscopic decompression. Knee Surg Sports Traumatol Arthrosc 15:908914. doi:10.1007/s00167-007-0332-x

32. Mardones RM, Gonzalez C, Chen Q, Zobitz M, Kaufman KR, Trousdale RT (2005) Surgical treatment of femoroacetabular impingement: evaluation of the effect of the size of the resection. J Bone Joint Surg Am 87:273-279. doi:10.2106/JBJS.D.01793

33. Ilizaliturri VM Jr, Chaidez PA, Valero FS, Aguilera JM (2005) Hip arthroscopy after previous acetabular osteotomy for developmental dysplasia of the hip. Arthroscopy 21:176-181. doi:10.1016/j.arthro.2004.09.011

34. Byrd JW, Jones KS (2003) Hip arthroscopy in the presence of dysplasia. Arthroscopy 19:1055-1060. doi:10.1016/j.arthro.2003. 10.010

35. McCarthy JJ, MacEwen GD (2007) Hip arthroscopy for the treatment of children with hip dysplasia: a preliminary report. Orthopedics 30:262-264

36. Suzuki S, Kasahara Y, Seto Y, Futami T, Furukawa K, Nishino Y (2004) Arthroscopy in 10 children with perthes disease. Pathologic changes of the synovium and the joint surface. Acta Orthop Scand 66:581-584

37. Bowen JR, Kumar VP, Joyce JJ III, Bowen JC (1986) Osteochondritis dissecans following Perthes disease. Arthroscopicoperative treatment. Clin Orthop Relat Res 209:49-56

38. Kuklo TR, Mackenzie WG, Keeler KA (1999) Hip arthroscopy in Legg-Calve-Perthes disease. Arthroscopy 15:88-92. doi:10.1053/ar.1999.v15.0150081

39. Medlock V, Rathjen KE, Montgomery JB (1999) Hip arthroscopy for the late Sequelae of Perthes Disease. Arthroscopy 15:552-553

40. Roy DR (2005) Arthroscopic findings of the hip in new onset hip pain in adolescents with previous Legg-Calve-Perthes disease. J Pediatr Orthop B 14:151-155

41. Roy DR The spectrum of intra-articular findings of the symptomatic hip with MED/SED. Manuscript submitted for publication

42. Mackenzie WG, Bassett GS, Mandell GA, Scott CI Jr (1990) Avascular necrosis of the hip in multiple epiphyseal dysplasia. J Pediatr Orthop 9:666-671 
43. Futami T, Kasahara Y, Suzuki S, Seto Y, Ushikubo S (2002) Arthroscopy for slipped capital femoral epiphysis. J Pediatr Orthop 12:592-597

44. Rab GT (1999) The geometry of slipped capital femoral epiphysis: implications for movement, impingement and corrective osteotomy. J Pediatr Orthop 19:419-424. doi:10.1097/00004694199907000-00001

45. Leunig M, Casillas MM, Hamlet M, Hersche O, Nötzli H, Slongo $\mathrm{T}$ et al (2000) Slipped capital femoral epiphysis: early mechanical damage to the acetabular cartilage by a prominent femoral metaphysis. Acta Orthop Scand 71:370-375. doi:10.1080/000 164700317393367

46. Ruch DS, Sekiya J, Dickson Schaefer W, Koman LA, Pope TL, Poehling GG (2001) The role of hip arthroscopy in the evaluation of avascular necrosis. Orthopedics 24:339-343

47. Kloen P, Leunig M, Ganz R (2002) Early lesions of the labrum and acetabular cartilage in osteonecrosis of the femoral head. $\mathrm{J}$ Bone Joint Surg Br 84:66-69. doi:10.1302/0301-620X. 84B1.12191

48. McCarthy J, Puri L, Barsoum W, Lee J, Laker M, Cooke P (2003) Articular cartilage changes in avascular necrosis: an arthroscopic evaluation. Clin Orthop Relat Res 406:64-70. doi:10.1097/0000 3086-200301000-00011

49. Mullis BH, Dahners LE (2006) Hip arthroscopy to remove loose bodies after traumatic dislocation. J Orthop Trauma 20:22-26. doi:10.1097/01.bot.0000188038.66582.ed

50. Yamamoto Y, Ide I, Ono T, Hamada Y (2003) Usefulness of arthroscopic surgery in hip trauma cases. Arthroscopy 19:269273. doi:10.1053/jars.2003.50033

51. Keene GS, Villar RN (1994) Arthroscopic loose body retrieval following traumatic hip dislocation. Injury 25:507-510. doi:10.1016/0020-1383(94)90090-6

52. Owens BD, Busconi BD (2006) Arthroscopy for hip dislocation and fracture dislocation. Am J Orthop 35:584-587

53. Barrett IR, Goldberg JA (1989) Avulsion fracture of the ligamentum teres in a child. J Bone Joint Surg Am 71:438-439

54. Shea KP, Kalamchi A, Thompson GH (1986) Acetabular epiphysis-labrum entrapment following traumatic anterior dislocation of the hip in children. J Pediatr Orthop 6:215-219

55. Olsson O, Landin LA, Johansson A (1994) Traumatic hip dislocation with spontaneous reduction and capsular interposition. A report of 2 children. Acta Orthop Scand 65:476-479

56. Kashiwagi N, Suzuki S, Seto Y (2001) Arthroscopic treatment for traumatic hip dislocation with avulsion fracture of the ligamentum teres. Arthroscopy 17:67-69. doi:10.1053/jars. 2001.8024

57. Byrd JW (2006) The role of hip arthroscopy in the athletic hip. Clin Sports Med 25:255-278. doi:10.1016/j.csm.2005.12.007

58. Shindle MK, Voos JE, Heyworth BE, Mintz DN, Moya LE, Buly RI, Kelly BT (2007) Hip arthroscopy in the athletic patient: current techniques and spectrum of disease. J Bone Joint Surg Am 89(Suppl 3):29-43. doi:10.2106/JBJS.G.00603

59. Philippon MJ, Schenker M (2005) Athletic hip injuries and capsular laxity. Oper Tech Orthop 15:261-266. doi:10.1053/ j.oto.2005.07.001

60. Bharam S (2006) Labral tears, extra-articular injuries, and hip arthroscopy in the athlete. Clin Sports Med 25:279-292. doi:10.1016/j.csm.2006.01.003

61. Berend KR, Vail TP (2001) Hip arthroscopy in the adolescent and pediatric athlete. Clin Sports Med 20:763-768. doi:10.1016/ S0278-5919(05)70283-0

62. Philippon MJ, Schenker ML (2006) Arthroscopy for the treatment of femoroacetabular impingement in the athlete. Clin Sports Med 25:299-308. doi:10.1016/j.csm.2005.12.006

63. Fitzgerald RH Jr (1995) Acetabular labral tears. Diagnosis and treatment. Clin Orthop Relat Res 31:60-68
64. Santori N, Villar RN (2000) Acetabular labral tears: result of arthroscopic partial limbectomy. Arthroscopy 16:11-15. doi:10.1016/S0749-8063(00)90121-X

65. Byrd JW, Jones KS (2000) Prospective analysis of hip arthroscopy with 2-year follow-up. Arthroscopy 25:279-292

66. Kelly BT, Weiland DE, Schenker ML, Philippon MJ (2005) Arthroscopic labral repair in the hip: surgical technique and review of the literature. Arthroscopy 12:1496-1504. doi: 10.1016/j.arthro.2005.08.013

67. Philippon MJ (2006) New frontiers in hip arthroscopy: the role of arthroscopic hip labral repair and capsulorrhaphy in the treatment of hip disorders. Instr Course Lect 55:309-316

68. Parvizi J, Leunig M, Ganz R (2007) Femoroacetabular impingement. J Am Acad Orthop Surg 15:561-570

69. Siebenrock KA, Wahab KH, Werley S, Kalhor M, Leunig M, Ganz R (2004) Abnormal extension of the femoral head epiphysis as a cause of cam management. Clin Orthop Relat Res 418:5460. doi:10.1097/00003086-200401000-00010

70. Ganz R, Parvizi J, Beck M, Leunig M, Nötzli H, Siebenrock KA (2003) Femoroacetabular impingement: a cause for osteoarthritis of the hip. Clin Orthop Relat Res 417:112-120

71. Ganz R, Leunig M, Leunig-Ganz K, Harris WH (2008) The etiology of osteoarthritis. An integrated mechanical concept. Clin Orthop Relat Res 466:264-272. doi:10.1007/s11999-007-0060-z

72. Espinosa N, Rothenfluh DA, Beck M, Ganz R, Leunig M (2006) Treatment of femoro-acetabular impingement: preliminary results of labral refixation. J Bone Joint Surg Am 88:925-935. doi:10.2106/JBJS.E.00290

73. Sampson TG (2006) Arthroscopic treatment of femoroacetabular impingement: a proposed technique with clinical experience. Instr Course Lect 55:337-346

74. Myers SR, Eijer H, Ganz R (1999) Anterior femoroacetabular impingement after periacetabular osteotomy. Clin Orthop Relat Res 363:93-99. doi:10.1097/00003086-199906000-00012

75. Bould M, Edwards D, Villar RN (1993) Arthroscopic diagnosis and treatment of septic arthritis of the hip joint. Arthroscopy 9:707-708. doi:10.1016/S0749-8063(05)80513-4

76. Blitzer CM (1993) Arthroscopic management of septic arthritis of the hip. Arthroscopy 9:414-416. doi:10.1016/S0749-8063 (05)80315-9

77. Yamamoto Y, Ide T, Hachisuka N, Maekawa S, Akamatsu N (2001) Arthroscopic surgery for septic arthritis of the hip joint in 4 adults. Arthroscopy 17:290-297. doi:10.1053/jars.2001.20664

78. Chung WK, Slater GK, Bates EH (1993) Treatment of septic arthritis of the hip by arthroscopic lavage. J Pediatr Orthop 13:444-446

79. Kim SJ, Choi NH, Ko SH, Linton JA, Park HW (2003) Arthroscopic treatment of septic arthritis of the hip. Clin Orthop Relat Res 407:211-214. doi:10.1097/00003086-200302000-00030

80. El-Sayed AMM (2008) Treatment of early septic arthritis of the hip in children: comparison of results of open arthrotomy versus arthroscopic drainage. J Child Orthop 2:229-237. doi:10.1007/ s11832-008-0094-0

81. Bonnomet F, Clavert P, Abidine FZ, Gicquel P, Clavert JM, Kempf JF (2001) Hip arthroscopy in hereditary multiple exostoses: A new perspective in treatment. Arthroscopy 17:40e. doi:10.1053/jars.2001.22410

82. Okada Y, Awaya G, Ikeda T, Tada H, Kamisato S, Futami T (1989) Arthroscopic surgery for synovial chondromatosis of the hip. J Bone Joint Surg Br 71:198-199

83. Krebs VE (2003) The role of hip arthroscopy in the treatment of synovial disorders and loose bodies. Clin Orthop Relat Res 406:48-59. doi:10.1097/00003086-200301000-00009

84. Yen Y, Briggs KK, Philippon MJ, Maxwell B, Kuppersmith D (2006) Outcomes following hip arthroscopy in the pediatric patient. Paper 312, AAOS Annual Meeting, San Francisco 
85. Martin RL, Philippon M (2008) Evidence of reliability and responsiveness for the hip outcome score. Arthroscopy 24:676682. doi:10.1016/j.arthro.2007.12.011

86. Martin RL, Kelly BT, Philippon MJ (2006) Evidence of validity for the hip outcome score. Arthroscopy 22:1304-1311. doi:10.1016/j.arthro.2006.07.027

87. Wenger DE, Kendall KR, Miner MR, Trousdale RT (2004) Acetabular labral tears rarely occur in the absence of bony abnormalities. Clin Orthop Relat Res 426:145-150. doi:10.1097/01.blo.0000136903.01368.20

88. Beaule' PE, Clohisy JC, Schoenecker P, Kim YJ, Millis M, Trousdale RT (2007) Hip arthroscopy: an emerging gold standard. Arthroscopy 23:682. doi:10.1016/j.arthro.2007.03.007 